\title{
PERFIL E PROGNÓSTICO DE PACIENTES INTERNADOS EM UNIDADE DE TERAPIA INTENSIVA ATRAVÉS DA UTILIZAÇÃO DA ESCALA DE APACHE II
}

Profile and prognosis of patients in an intensive care unit through the APACHE II Scale

\author{
Irany Achiles Denti ${ }^{1}$; Diogo Francisco Pigatto ${ }^{2}$
}

${ }^{1}$ Enfermeiro, Mestre em Enfermagem pela UFSC, Doutor em Ciências da Saúde pela UNESC, Professor do Curso de Graduação em Enfermagem da Universidade Regional Integrada do Alto Uruguai e das Missões - URI Erechim.E-mail: iranyd@uricer.edu.br

${ }^{2}$ Enfermeiro, graduado pela Universidade Regional Integrada do Alto Uruguai e das Missões - URI Erechim.

RESUMO: As Unidades de Terapia Intensiva são destinadas a pacientes graves, com instabilidade de sistemas e aparelhos que potencialmente podem levar ao óbito. Para atender a essas demandas, tais unidades estão aparelhadas com equipamentos tecnológicos sofisticados, exigindo dos profissionais capacidade cognitiva diferenciada, assim como disposição para aprender constantemente. Desta forma, são necessárias atividades de avaliação diária e individualizadas para estimar a gravidade para os pacientes internados nessa unidade. Neste sentido, o presente estudo descreve o perfil e gravidade de pacientes em Unidade de Terapia Intensiva (UTI), através da utilização da Escala de APACHE II. Os dados necessários para e execução do projeto foram coletados no prontuário eletrônico em 2018. Foram avaliadas 50 pessoas com média de idade de 59,76 $\pm 20,50$ anos. O escore APACHE II foi aplicado em um único momento para pacientes em uso de suporte ventilatório mecânico. No entanto, também foi acompanhado o desfecho (alta da unidade ou óbito). O escore APACHE II médio foi de $13,54 \pm 4,74$ e por esta média o risco de morte pode ser projetado entre $8 \%$ e $12 \%$ e este mostrou significância estatística $\mathrm{p}<0,05$ para o desfecho (alta/óbito) correlacionado com os níveis de creatinina e com a Pressão Arterial Média.

Palavras-chave: Unidade de Terapia Intensiva. APACHE. Mortalidade. 


\begin{abstract}
Intensive care units are intended to severe patients with instability of systems and devices that can potentially lead to death. In order to meet these demands, these units are equipped with sophisticated technological equipment, requiring differentiated cognitive skills from professionals, as well as willingness to constantly learn. Thus, daily and individualized assessment activities are necessary to estimate the severity for patients admitted to this unit. In this sense, the present study describes the profile and severity of patients in the Intensive Care Unit (ICU), using the APACHE II Scale. The necessary data for the execution of this project were collected from the electronic medical record in 2018. Fifty people with an average age of 59.76 \pm 20.50 years old were assessed. The APACHE II score was applied in a single moment to patients using mechanical ventilatory support. However, the outcome was also monitored (discharge from the unit or death). The average APACHE II score was $13.54 \pm 4.74$ and based on this average the risk of death can be projected between $8 \%$ and $12 \%$ and this showed statistical significance $\mathrm{p}<0.05$ for the outcome (discharge / death) correlated with creatinine levels and Mean Arterial Pressure.
\end{abstract}

Keywords: Intensive Care Unit. APACHE. Mortality.

\section{Introdução}

As Unidades de Terapia Intensiva (UTI) estão entre os espaços onde se requer vigilância constante aos pacientes ali internados, pois estes se encontram em um quadro mais grave, com iminente risco de óbito, necessitando de intervenções de enfermagem durante as 24 horas do dia. Neste contexto, o cenário que a UTI repassa para as pessoas é de um local de muita tristeza, angústia, dor física, rotulado apenas como um ambiente relacionado ao sofrimento e à morte. (PROENÇA; AGNOLO, 2011).

No momento em que um integrante da família encontra-se internado em uma UTI, os demais membros estão cientes de que este local é destinado a pacientes gravemente enfermos e que este período é um dos momentos mais difíceis e significativos de uma família, pois se sabe que a UTI é um local onde se encontram pacientes graves, que necessitam de um cuidado intensivo.
Neste sentido faz-se necessária a observação de normas e rotinas diferentes de outros setores de um hospital, tais como: horário de visitas muito curto, número delimitado de visitantes por doente, horários que dificultam a presença de familiares e as informações sobre o quadro do paciente são restritas, e geralmente são informadas apenas pelo médico plantonista ou pelo médico assistente (NASCIMENTO; TRENTINI, 2012).

As UTIs têm como finalidade promover a recuperação de doentes com alto risco ou graves por meio de suporte ventilatório, monitorização hemodinâmica e controle dos diversos sistemas orgânicos, utilizando recursos tecnológicos e humanos. Conta com a presença de equipe de enfermagem e médica em tempo integral, além de suporte de outros profissionais, como fisioterapeutas, nutricionistas e psicólogos, entre outros (BRASIL, 2010).

Com isso faz-se necessário avaliar estes pacientes utilizando instrumentos fidedig- 
nos para avaliação. Um dos métodos mais comumente utilizados são escalas, pelas quais se pode mensurar o estado geral do paciente ali internado. Para este fim, a Escala de APACHE II é utilizada para determinar a gravidade dos pacientes, buscando identificar, junto a outros fatores, o prognóstico bem como o risco de mortalidade no sentido de conduzir a assistência dos profissionais de saúde (FREITAS, 2010). O uso dessa escala tem por objetivo determinar a gravidade da doença e analisar a mortalidade hospitalar, através de valores obtidos nas primeiras 24 horas de internação através de informações padronizadas (CARDOSO, 2012).

Conforme Knaus (1985), a Escala de APACHE II baseia-se em 12 variáveis fisiológicas (Temperatura Corporal, Pressão Arterial Média (PAM), Frequência Cardíaca (FC), Frequência Respiratória (FR), pH, Oxigenação, Sódio Sérico, Potássio Sérico, Creatinina Sérica, Hematócrito, Leucócitos, da Escala de Coma Glasgow), podendo ser pontuada entre $0<34$ pontos MALIK; WANI, 2010).

A utilização de escalas em UTIs tem permitido uma avaliação do desempenho das unidades, tendo como objetivo maior a eficiência do tratamento utilizado. Essas escalas são utilizadas como instrumento facilitador a fim de estimar o grau de risco de mortalidade de pacientes internados na Unidade de Terapia Intensiva, a fim de possibilitar um dimensionamento da enfermagem visando sempre a qualidade da assistência prestada (NOGUEIRA et al., 2007).

De modo geral, há entre os profissionais da saúde entendimento de que os pacientes mais graves requerem assistência qualificada quanto a recursos humanos e de equipamentos. Contudo, por meio da relação do índice obtido da Escala de APACHE II, pode-se ter uma medida da condição do paciente e a necessidade de cuidados de enfermagem, conforme o resultado obtido com sua aplicação (NOGUEIRA et al., 2007).

A Escala de APACHE II tem sido utilizada amplamente no Brasil e no Mundo. O Ministério da Saúde, a partir da portaria $\mathrm{n}^{\circ} 3.432$, recomenda que a Escala de APACHE II seja utilizada por UTIs (BRASIL, 1998). A partir do ano de 2010, a Resolução da Diretoria Colegiada (RDC) $\mathrm{n}^{\circ} 7$ de 24 de fevereiro de 2010 recomenda que todas as UTI utilizem a escala como classificação de severidade da doença (BRASIL, 2010). Desta forma o estudo atual descreve o perfil e prognóstico de pacientes em Unidade de Terapia Intensiva (UTI), por meio da utilização da Escala de APACHE II.

\section{Metodologia}

Trata-se de um estudo de coorte prospectivo realizado em uma UTI de um hospital do norte do Rio Grande do Sul, com 50 prontuários de pacientes internados nesta unidade, maiores de 18 anos e um uso de ventilação mecânica, no período de junho a agosto de 2018. Os dados clínicos e laboratoriais foram coletados dos prontuários, disponíveis no sistema de informação, durante o período de internação nesta unidade. O estudo foi aprovado pelo Comitê de Ética e Pesquisa da URI Erechim, sob o número 2.671.173. Foram utilizados, para este estudo, idade, sexo, motivo da internação ou diagnóstico médico, doenças pré-existentes, temperatura axilar $\left({ }^{\circ} \mathrm{C}\right)$, pressão arterial média em $\mathrm{mmHg}$, frequência cardíaca, frequência respiratória, fração de oxigênio inalado, $\mathrm{pH}$ do sangue arterial, taxas de sódio e potássio sérico, creatinina sérica, hematócrito e leucócitos totais. A classificação e severidade da doença foi efetuada de acordo com KNAUS et al. (1985), em cujo trabalho são preconizadas análise de funções fisiológicas e estas são transformadas em escores. 
Os dados foram coletados após 24 horas de internação. Nos pacientes com lesão do $\mathrm{SNC}$, fazendo uso de sedativos e/ou relaxantes musculares, o escore da Escala de Coma de Glasgow foi considerada normal. $\mathrm{Na}$ ausência de dados de exames laboratoriais, a classificação foi considerada como normal. Foram excluídos pacientes menores de 18 anos de idade, com insuficiência renal crônica, transplantados renais definidos por creatinina acima de $2 \mathrm{mg} / \mathrm{dL}$ a admissão, dialisados por intoxicação exógena.

Os dados foram analisados e expressos por meio de estatística descritiva com média e desvio padrão. O cálculo de risco indicado segundo o modelo exposto (Escore de APACHE II A+B+C) foi exposto através de escores. Contudo, no presente estudo não utilizamos a Escala de Coma de Glasgow para compor o escore, visto que os pacientes-alvo do estudo estavam sob terapia com analgesia e sedação. Para estimar a significância estatística correlacionada ao desfecho foi utilizado o teste Mann-Witney com intervalo de confiança de $95 \%$.

\section{Resultados}

Os dados inseridos a seguir referem-se à avaliação de risco por meio da Escala de APACHE II, em que foram coletados dados de cinquenta pacientes ( 30 mulheres e 20 homens) internados em uma Unidade de Terapia Intensiva (UTI) adulto. Dados-alvo desta análise dizem respeito a idade, sexo, motivo da internação ou diagnóstico médico, doenças pré-existentes, falência de órgãos, temperatura axilar $\left({ }^{\circ} \mathrm{C}\right)$, pressão arterial média em $\mathrm{mmHg}$, frequência cardíaca, frequência respiratória, fração de oxigênio inalado, $\mathrm{pH}$ do sangue arterial, taxas de sódio e potássio sérico, creatinina sérica, hematócrito e leucócitos totais.

Inicialmente serão mostrados os resultados da média e desvio padrão (DP).
Pos-teriormente serão apresentados dados pertinentes a correlações. A média de idade foi $59,76 \pm 20,50$ anos; temperatura $36,46 \pm 0,83$; PAM 78,68 $\pm 22,57$; frequência cardíaca $101 \pm 20 \mathrm{bpm}$; frequência respiratória $18 \pm 5,3$ movimentos respiratórios por minuto; índice de oxigenação 199 $\pm 11,2$ definida pela $\mathrm{PaO}_{2}$ sobre a $\mathrm{FiO}_{2}$; onde é considerado como adequado $>200$; a média do $\mathrm{pH}$ arterial foi $7,29 \pm 0,11$; sódio sérico $141,58 \pm 14,60$; potássio sérico 3,90 $\pm 0,71$; taxa de creatinina $1,67 \pm 0,91$; hematócrito $34,49 \pm 9,43$ leucócitos totais $16,39 \pm 9,21$; bicarbonato $26,27 \pm 6,77$ e média do escore de APACHE 13,54 $\pm 4,74$. Do público-alvo do estudo, $48 \%$ evoluíram para óbito e $52 \%$ obtiveram alta da unidade. Os principais motivos para a internação na unidade, mostrados na Figura 1A, foram pós-operatório com $22,5 \%$ e doença pulmonar obstrutiva crônica com 34\%. Contudo, também merece destaque para as doenças cardiovasculares (DCV), insuficiência respiratória (Ins.Resp) e parada cardiorrespiratória (PCR). Neste aspecto os números absolutos e as porcentagens superam $100 \%$, visto que em alguns pacientes havia mais de uma doença de base e que motivou a internação.

$\mathrm{O}$ escore de APACHE II médio registrado no estudo foi $13,54 \pm 4,74$, sendo que o escore considerado para este instrumento está compreendido de zero a 35. No estudo atual não identificamos escores extremos como zero ou acima de 25 , conforme mostrado na Figura 1B.

Muito embora não tenhamos encontrado escores acima de 25, a mortalidade entre o grupo pesquisado foi de $48 \%$. No entanto, os dados apontam para a maior incidência de mortalidade proporcional para os grupos que obtiverem escores mais elevados, evidenciados na Figura 1C. O escore de APACHE mostrou significância estatística $p<0,05$ para o desfecho (alta/óbito) correlacionado com os níveis de creatinina e com a PAM. 
Figura 1 - Causas de internação, classificação de APACHE, mortalidade e índice de oxigenação

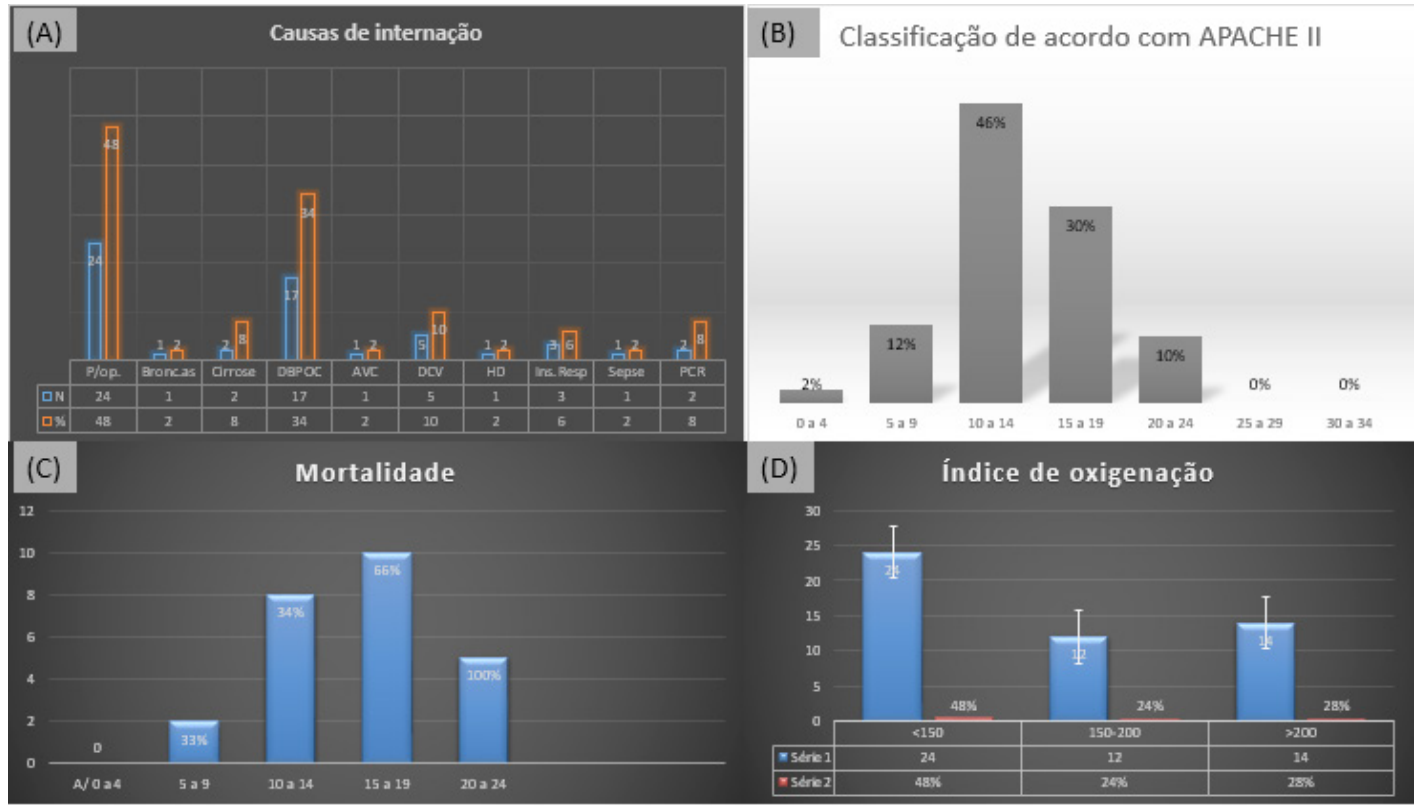

Figura 1A - P/op = pós-operatório, Bronco.a = broncoaspiração, $\mathrm{DBPOC}=$ doença pulmonar obstrutiva crônica, $\mathrm{AVC}=\mathrm{acidente}$ vascular encefálico, $\mathrm{DCV}=$ doença cardiovascular, $\mathrm{HD}=$ hemorragia digestiva, ins.Res $=$ insuficiência respiratória, $\mathrm{PCR}=$ parada cardiorrespiratória.

O risco global de morte hospitalar variou de acordo com a doença de base e que foi o motivo principal da admissão na Unidade de Terapia Intensiva. Por exemplo, a maior incidência de mortalidade foi evidenciada em pacientes no pós-operatório imediato e com insuficiência respiratória, cujos escores de APACHE II oscilaram de 10 a 24. Os escores com menor pontuação apresentaram menor taxa de mortalidade hospitalar observada em pacientes com sepse, AVC e parada cardiorrespiratória (PCR).

Muito embora a média do índice de ventilação no estudo atual esteja próxima aos padrões ideais (199), neste se verifica que em $48 \%$ estes índices estão abaixo do recomendado, indicando que a $\mathrm{PaO}_{2}$ está baixa e, por este motivo, está sendo utilizada $\mathrm{FiO}_{2}$ elevada para tentar suprir as demandas fisiológicas, assim como para conpensar os possíveis déficits de trocas gasosas (Figura 1D). Estes achados, em sua maioria discordantes das condições fisiológicas ideais podem estar correlacionados com a condição clínica e eventualmente a falta da aplicação de protololos padronizados para atender a pacientes nestas condições clínicas.

Em pacientes graves e em uso de ventilação mecânica a definição da Fração de Oxigênio $\left(\mathrm{FiO}_{2}\right)$ a ser adicionada ao ar, necessária para manter a saturação tecidual dentro de padrões fisiológicos, segundo Kallstrom (2002), parte-se do indicador ideal $\left(\mathrm{FiO}_{2}\right.$ de $25 \%$ ) ou basal $\left(\mathrm{FiO}_{2} 40 \%\right)$. Para avaliar o índice de oxigenação utiliza-se a relação $\mathrm{PaO}_{2} /$ $\mathrm{FiO}_{2}$. $\mathrm{A} \mathrm{PaO}_{2}$, expressa na gasometria arterial, exprime a eficácia das trocas de oxigênio entre os alvéolos e os capilares pulmonares e depende diretamente da pressão parcial de oxigênio nos alvéolos, da capacidade de difusão pulmonar desse gás e da relação ventilação/perfusão pulmonar. $\mathrm{A} \mathrm{FiO}_{2}$ é definida 
como a fração de oxigênio adicionado ao ar que será ofertado ao paciente por meio de um ventilador mecânico. Para fins práticos, este cálculo estabelece como padrões ideais para o índice de oxigenação valores $>200$ e aceitáveis entre 150 a 200 (MACINTYRE et al., 2005).

O equlíbrio ácido-base é um fator importante e determinante para a manutenção da homeostasia das funções fisiológicas. Os dados do estudo atual (Figura 2E) mostram que $60 \%$ dos pacientes, no momento da coleta de dados, foram classificados com acidose, $34 \%$ em equilíbrio e $6 \%$ com alcalose. A análise destes dados mostra que a maioria dos pacientes $(66 \%)$ apresentaram desequilíbrio ácido-base. Quanto a acidose, os dados do estudo não oferecem elementos para definir se está sendo determinada por distúrbio respiratório ou metabólico. No entanto, a alcalose possivelmente esteja relacionada a hiperventilação ou a administração de bicarbonato de sódio. A descompensação ácido-base pode refletir distúrbios devidos a hipo ou hiperventilação, assim como na incapacidade dos mecanismos compensatórios como a secreção de bicarbonato, ação das proteínas e da hemoglobina, assim como da função renal para manter a homeostasia ácido-base, neste caso determinando a acidose metabólica (RASTEGAR, 2007).

O bicarbonato, secretado pela porção exócrina do pâncreas, juntamente com a hemoglobina e proteínas plasmáticas, são considerados os tampões orgânicos, auxiliando a manutenção do equilíbrio ácidobase. Estes são necessários para manter a homeostasia ácido-base, tendo como valores de referência 22 a $26 \mathrm{mEq} / \mathrm{L}$ (GUYTON; HALL, 2006). As taxas de bicarbonato sérico, mostradas na Figura $2 \mathrm{~F}$ correlacionadas com o $\mathrm{pH}$ oferecem uma ideia clara referente ao desequilíbrio ácido-base. Neste sentido é importante ponderar que alguns destes achados, principalmente os valores considerados acima do normal, podem estar relacionados com a administração deste eletrólito na reanimação cardiopulmonar. A regulação da excreção de bicarbonato fica por conta da função renal e, no caso do estudo atual, é possível

Figura 2 - Equilíbrio ácido-base, bicarbonato sérico, taxas de creatinina e pressão arterial média

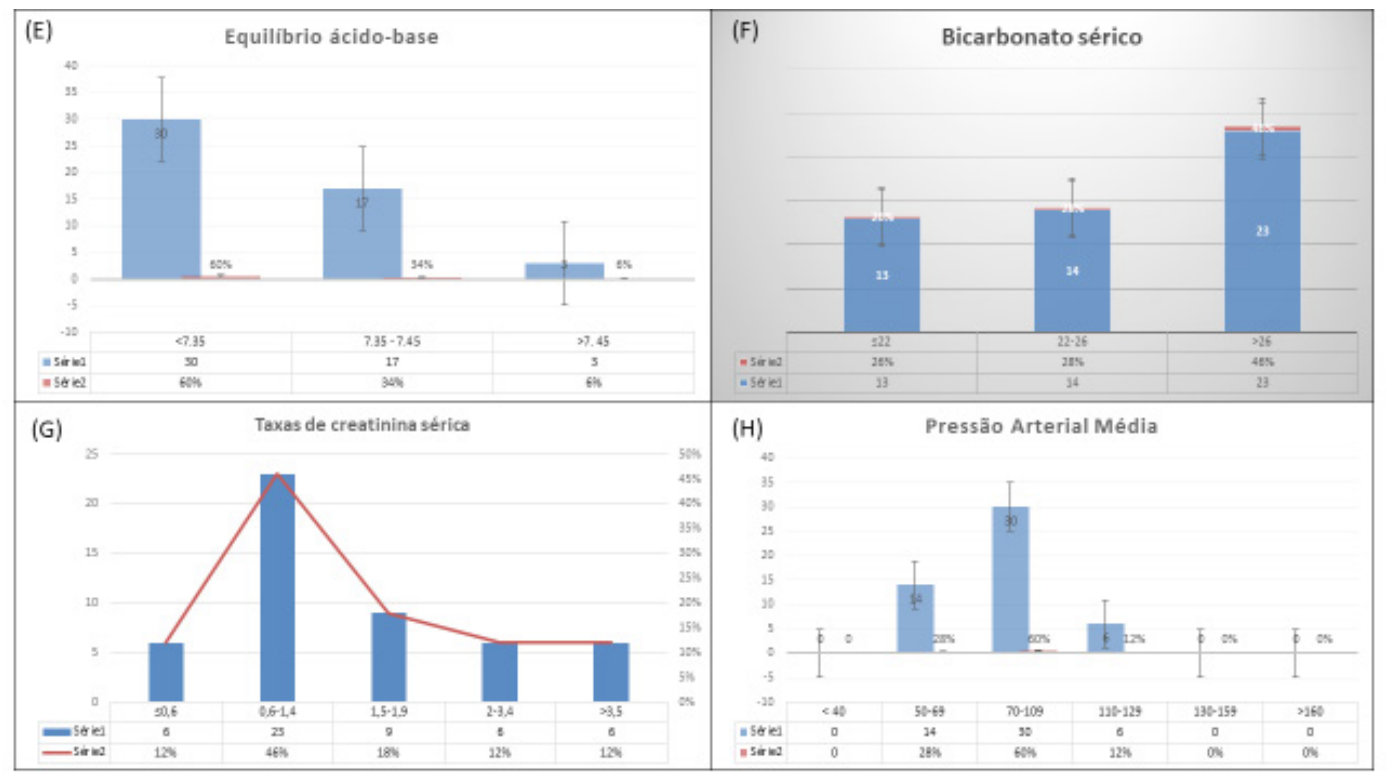


que parte significativa deste desequilíbrio esteja correlacionada à insuficiência renal, mostrada na Figura 2G. Outras possibilidades para os achados do estudo atual podem ser advindas da administração de bicarbonato de sódio em paciente com acidose orgânica. Neste caso ocorre a elevação da concentração sérica de bicarbonato, lavando a alcalinemia e alcalose metabólica, sem resolver o problema principal que é a alta concentração de ácidos orgânicos (ROCHA, 2009).

A função renal é um parâmetro importante para avaliar alguns aspectos do metabolismo, assim como da função excretora propriamente dita. Os dados do universo do estudo mostram que esta função foi afetada em pelo menos $42 \%$, evidenciado pelas taxas de creatinina expostas na Figura 2G. Para esta classificação foram utilizados os parâmetros indicados pelo instrumento de coleta de dados. Visto que a creatinina é um produto da degradação da creatina fosforilada no tecido muscular, esta taxa está diretamente relacionado ao volume da massa muscular e, por este motivo, possivelmente alguns pacientes classificados com a função alterada $(1,5-1,9)$ poderiam estar com a função renal preservada, contrariamente ao que expusemos no Figura 2G.

Para esta classificação a referência mais utilizada para mulheres é 0,5 a $1,0 \mathrm{mg} / \mathrm{dL}$ e para homens 0,7 a 1,2 mg/dL (MENNA, 2010). No entanto, segundo Ferri (2018), taxas de creatinina de $2,0 \mathrm{mg} / \mathrm{dl}$ poderiam ser consideradas fisiológicas para um homem com avantajada massa muscular e $0,7 \mathrm{mg} / \mathrm{dl}$ poderia indicar doença renal em uma mulher idosa e com pouca massa muscular. Por outro lado, todas as referências apontam para a falência renal quando os níveis de creatinina sérica ultrapassam 2,0mg/dl, encontrada em $24 \%$ dos pacientes do estudo.

A pressão arterial é um dos mecanismos fisiológicos mais importantes para a manutenção da homeostasia celular através do aporte de oxigênio e nutrientes, assim como para a remoção de excretas provenientes do metabolismo (KIM et al., 2016). O controle da pressão arterial (PA) em curto prazo, durante períodos de segundos ou de minutos, é realizado quase que integralmente por reflexos nervosos executado pelos barorreceptores. Esses sinais são originados no bulbo, percorrendo o sistema nervoso autonômico para provocar, dependendo da condição, (a) lentificação ou aumento da frequência cardíaca, (b) aumento ou redução da força de contração cardíaca, (c) contração ou dilatação das arteríolas e (d) contração ou dilatação das grandes veias que, em conjunto, atuam no sentido de fazer com que a pressão arterial seja mantida em cifras fisiológicas (GUYTON; HALL, 2006.

O cálculo da pressão arterial média (PAM) é efetuado utilizando-se a pressão arterial sistólica, mais duas vezes a pressão diastólica, dividido por três. Para o estudo atual os parâmetros utilizados formam os indicados pelo instrumento de coleta de dados e este refere como parâmetros fisiológicos cifras de $70-109 \mathrm{mmHg}$.

De acordo com os dados do estudo, expostos na Figura 2H, 60\% dos pacientes mantinham parâmetros de pressão arterial média considerados fisiológicos. Por outro lado, $28 \%$ apresentaram cifras abaixo e $12 \%$ acima das cifras consideradas fisiológicas. Estes resultados refletem, até certo ponto, as dificuldades em manter a pressão arterial dentro de cifras fisiológicas em pacientes gravemente enfermos. Torabi et al. (2016) referem que a pressão arterial baixa foi independentemente associada com mortalidade em pacientes internados em unidades de terapia intensiva.

\section{Discussão}

Desde a introdução, em meados do século passado, de equipamentos de ventilação me- 
cânica, além de outros instrumentos, assim como a utilização de tecnologias de ponta, as Unidades de Terapia Intensiva proporcionaram a manutenção da vida em condições muitas vezes descritas como artificiais. Muitas pessoas foram e são beneficiadas com estes avanços tecnológicos e seguramente vários questionamentos referentes ao prolongamento da vida também são pertinentes. Partindo desta premissa, fez-se necessário o desenvolvimento de instrumentos que tivessem valor classificatório assim como preditivo para que as intervenções de cuidado pudessem ser mais eficientes e direcionadas para solucionar os problemas mais iminentes e que estiverem colocando a vida em risco.

Adicionalmente, estas unidades são utilizadas para que as funções fisiológicas sejam vigiadas ininterruptamente por profissionais qualificados e auxiliados por equipamentos de ponta, buscando evidenciar as alterações fisiológicas, proporcionando a escolha da terapia ideal para cada situação e desta forma melhor tratamento, elevando os índices de sobrevida.

Com a introdução de tecnologias de ponta e de profissionais qualificados para operar estes instrumentos, estas unidades se tornaram onerosas para o sistema de saúde pública. Mesmo assim, o que se verifica no dia a dia é o aumento na procura por leitos nestas unidades em consequência do agravamento das condições clínicas. Torna-se importante dispor de instrumentos que possam oferecer dados quantitativos seguros para que a equipe de saúde possa organizar ações específicas, visando a redução dos possíveis danos ou aumento das sequelas da população sob seus cuidados. Neste sentido, foram desenvolvidos instrumentos de medida de fácil aplicabilidade e de baixo custo visando a estratificação de risco, como a Escala de APACHE II.

Essa escala foi desenvolvida por KNAUS et al. (1985), visando propiciar a avaliação prognóstica de pacientes internados em Unidades de Terapia Intensiva com o objetivo de estabelecer estratégias de tratamento dos doentes graves, reduzir custos, melhorar sobrevida e humanizar condutas terapêuticas, visando a redução das taxas de mortalidade nestas unidades (SILVA; SOUSA; PADILHA, 2012).

De acordo com o objetivo deste estudo, foi avaliada uma população de 50 pacientes (30 mulheres e 20 homens), com predomínio do sexo feminino, cuja média de idade foi 59 anos. Nesta pesquisa a taxa de mortalidade foi de $48 \%$, podendo ser considerada dentro das taxas de mortalidade das UTIs, mundialmente aceitas. Kock et al. (2014), em estudo com pacientes em uso de ventilação mecânica, avaliaram o desfecho óbito/alta utilizando a Escala de APACHE II, cujos dados apontaram óbito em 53,6\%. Em estudo conduzido por Vieira (2011), a taxa de óbito foi de $50,7 \%$, dados que se assemelham ao estudo atual; Freitas (2010) encontrou taxa de mortalidade de 58,2\%, ficando acima da média geral.

Outros estudos, como os descritos a seguir, utilizando o mesmo método para avaliação, mostraram resultados significativamente diferentes. Contudo, possivelmente para esses estudos, os autores consideraram todos os pacientes internados na unidade de terapia intensiva, diferentemente do estudo atual, que incluiu somente pacientes em uso de ventilação mecânica. Nestas condições, no estudo de Rodriguez et al. (2016) a taxa de mortalidade geral foi $20,4 \%$. Oliveira et al. (2010) encontraram taxa de mortalidade geral de $13,46 \%$ e as principais causas para os óbitos foram o tempo de internação prolongado em Unidade de Terapia Intensiva, APACHE II $>11$, em uso de traqueostomia e necessidade de reintubação.

Um dos motivos possíveis, no estudo atual, que podem justificar as altas taxas de mortalidade deve-se ao grande número de 
pacientes recebidos na unidade, provindos de várias localidades e muitas vezes com patologias graves, com comprometimento de aparelhos e sistemas vitais, sem tratamento adequado e condições clínicas extremamente graves. Em relação ao grupo patológico, o predomínio de internações na UTI foi do grupo com doenças ou complicações da função renal, seguido por complicações do aparelho respiratório e cardiovascular. Em muitos casos, a doença renal não foi confirmada como a causa principal da internação na unidade.

Em relação aos escores da Escala de APACHE II, houve variabilidade, permanecendo um escore médio de 13,54, assemelhando-se aos escores publicados por Cardoso; Matsuo; Bonametti; Grion (2002) que apresentaram um escore médio de 16,9, enquanto Moreno e Morais (1997), e Zanon, Caovila e Michel (2008), encontraram escores médios de 19,6 e 18, respectivamente, acima do resultado encontrado neste estudo. Quanto a mortalidade, o estudo atual mostrou que escores de APACHE II mais elevados foram correlacionados com maior índice de mortalidade, estando em consonância com os resultados encontrados por Naved; Siddiqui; Khan 2011), em que os escores mais elevados (>31) foram significativamente correlacionados com a mortalidade.

Muito embora a Escala de Coma de Glasgow (ECG) seja indicada para avaliar algumas funções neurológicas e consta como uma das variáveis a serem utilizadas na Escala de APACHE II, esta não foi utilizada no estudo atual, visto que os pacientes estavam sob sedação e analgesia.

As escalas de prognósticos, além de avaliar riscos de mortalidade para patologias nas UTIs, são importantes para indicar caminhos e estratégias de trabalho, otimização do trabalho das equipes multidisciplinares, de acordo com os perfis encontrados para cada unidade, visando a proporcionar atendimento tecnicamente ideal e humanizado para pacientes e familiares (CHIAVONE; SENS, 2003).

\section{Conclusões}

Com base nos resultados obtidos com a pesquisa, verificou-se que o escore elevado de APACHE II, PAM e níveis de creatinina estiveram associados à maior taxa de mortalidade. Estes indicadores apontam caminhos potenciais para os profissionais componentes das equipes investirem visando a redução das taxas de mortalidade. A consciência e a compreensão dessas características permitem à equipe de saúde planejar ações de cuidados que atentem-se a estes fatores como forma de maximizar a possibilidade da melhora dos indicadores clínicos e, consequentemente, diminuir os níveis de mortalidade da unidade. Adicionalmente, esse conhecimento traz à equipe a possibilidade de subsídio em forma de evidência para projetar propostas de melhorias em termos de estrutura e tecnologias duras, a fim de obter resultados satisfatórios para a instituição e para o paciente.

Este estudo apresentou como fragilidades a carência de pesquisas recentes sobre a temática, dificultando comparações entre os resultados, assim como análise do tema. Dessa forma, recomenda-se que novos estudos sejam feitos sobre esse tema para desenvolver o conhecimento acerca da escala, como usá-la e os resultados obtidos a partir da sua aplicação. Outra limitação encontrada foi a Escala de Coma de Glasgow, pois não se tem conhecimento sobre os parâmetros reais, uma vez que todos os pacientes eram sedados, dificultando sua aplicação e obtenção de resultados que atendam a este parâmetro. 


\section{REFERÊNCIAS}

BRASIL. Ministério da Saúde. Portaria no 3.432, de 12 de agosto de 1998. Estabelece critérios de classificação para as Unidades de Tratamento Intensivo - UTI. Brasília, 1998.

BRASIL. Ministério da Saúde. Agência Nacional de Vigilância Sanitária. Resolução RDC nº 7, de 24 de fevereiro de 2010. Dispõe sobre os requisitos mínimos para funcionamento de Unidades de Terapia Intensiva. Brasília; 2010.

CARDOSO, L.T.Q.; MATSUO, T.; BONAMETTI, A.M.; GRION, C. M.C. Avaliação do risco de mortalidade através do APACHE II para CTI de um hospital-escola público. Rev. Bras. Terapia Intensiva, v. 8, n.3, p. 85-94, 2002.

CARDOSO, L.G.S. Tese - Desempenho do Apache II medido na saída da UTI na previsão da letalidade, v. 21, n.3, p. 1-9, 2012.

CHIAVONE, P.A; SENS, Y.A. Evaluation of Apache II system among intensive care patients at a teaching hospital. São Paulo Med J, v. 121, n.2, p.53-57, 2003.

FERRI, F. Ferri's Clinical Advisor. E-Book: 5 Books in 1.: Elsevier Health Sciences. p. 294.

FREITAS, R.F.S.E. Perfil e gravidade dos pacientes das unidades de terapia intensiva aplicação e prospectiva do escore de APACHE II. Rev. Latino-Am. Enfermagem, v. 18, n.3, p.20-26, Maio/ Junho, 2010.

GUYTON, A.C.; HALL, J. Tratado de fisiologia Médica. 11. ed. Rio de Janeiro: Elsevier, 2006.

KALLSTROM, T.J. American Association for Respiratory Care (AARC). AARC Clinical Practice Guideline: oxygen therapy for adults in the acute care facility--2002 revision \&

Update. Respir Care, v.47, n.6, p.717-20, 2002.

KIM, S.Y. et al. Validation of the Shock Index, Modified Shock Index, and Age Shock Index for Predicting Mortality of Geriatric Trauma Patients in Emergency Departments. J Korean Med Sci, v. 31, n.12, p. 2026-2032, 2016.

KNAUS, W.A. et al. APACHE II: A Severity of disease classification system. Crit Care Med, v.13, n.10, p.818-29, 1985.

KOCK, K.S.; GUADAGNIN, F.; MACHADO, M. O.; MAURICI, R. Comparação do APACHE II e PCR como preditores de mortalidade em pacientes hospitalizados em UTI. Rev. da AMRIGS, Porto Alegre, v. 58, n.3, p. 182-186, 2014.

MACINTYRE, N.R. et al. Management of patients requiring prolonged mechanical ventilation:

Chest, v.128, n.6, p. 3937-54, 2005.

MALIK, A.A.; WANI, K.A. Mannheim Peritonitis Index and APACHE II - Prediction of out come in patients peritonitis. Ulus Travma Acil Cerrahi Derg, v. 16, n.1, p.27-32, 2010.

MENNA, C. Nephrology: Clinical Cases Uncovered.: John Wiley \& Sons. 2010. p. 28

MORENO, R.; MORAIS, P. Outcome prediction in intensive care: results of a prospective, multicentre, Portugueses study. Intensive Care Med, v. 23, n. 2, p.77-86, 1997.

NASCIMENTO, E. R. P.; TRENTINI, M. O Cuidado de Enfermagem na Unidade de Terapia Intensiva (UTI). Teoria Humanística de Paterson e Zderad. Rev. Latino-Am Enfermagem, v.12, n.2, p. 250-257, 2012. 
NAVED, A.S.; SIDDIQUI, S.; KHAN, F.H. APACHE-II Score Correlation With Mortality And Length Of Stay. In An Intensive Care Unit. Journal of the College of Physicians and Surgeons Pakistan, v. 21, n.1, p. 4-8, 2011.

NOGUEIRA, L. S. et al. Nursing Activities Score: comparação com o Índice APACHE II e a mortalidade em pacientes admitidos em unidade de terapia intensiva. Rev. Bras. Ter. Intensiva, v. 19, n. 3, p. 327-330, 2007.

OLIVEIRA, A.B.F. de et al. Fatores associados à maior mortalidade e tempo de internação prolongado em uma unidade de terapia intensiva de adultos. Rev Bras. Ter Intensiva, v. 22, n.3, p.250-256, 2010.

PROENCA, M. O.; AGNOLO, C. M. D. Internação em unidade de terapia intensiva: percepção de pacientes. Rev. Gaúcha Enfermagem, v. 32, n.2, p. 279-86, 2011.

RASTEGAR, A. Use of the DeltaAG/DeltaHCO3 - ratio in the diagnosis of mixed acid-base disorders. J Am Soc Nephrol, v. 18, n. 9, p. 2429-31, 2007.

ROCHA, P.N. Uso de bicarbonato de sódio na acidose metabólica do paciente gravemente enfermo. J Bras Nefrol, v.31, n.4, p.297-306, 2009.

RODRIGUEZ, A.H. et al. Características epidemiológicas e causas de óbitos em pacientes internados em terapia intensiva. Rev Bras Enfermagem, v.69, n.2, p.210-4, 2016.

SILVA, M.C.M.; SOUSA, R.M.C.; PADILHA, K.G. Patient Destination after Discharge from Intensive Care Units: wards or intermediate care units? Rev Latino-Am Enfermagem, v. 23, n.1, p.22-7, 2012.

TORABI, M. et al. Shock index, modified shock index, and age shock index for prediction of mortality in Emergency Severity Index level 3. The American Journal of Emergency Medicine, v. 34, n.11, p. 2079-2083, 2016.

VIEIRA, M.S. Perfil geográfico e clínico de paciente admitido na UTI através da Regulação de Internações Hospitalar. Com. Ciências da Saúde, v. 18, n.1, p. 201-210, 2011.

ZANON, F.; CAOVILA, J.J.; MICHEL, S.R. Sepse na Unidade de Terapia Intensiva: Etiologia, Fatores, Prognóstico e Mortalidade. Ver. Brasileira de Terapia Intensiva, v. 20. n.2, p. 128-134, 2008. 
